\title{
POTENSI ZEOLIT ALAM DAN CaO DARI CANGKANG TELUR AYAM SEBAGAI KATALIS DALAM PEMBUATAN BIODIESEL DARI TREATED WASTE COOKING OIL
}

\author{
POTENTIAL OF NATURAL ZEOLITE AND CAO FROM THE CHICKEN EGGSHELLS \\ AS CATALYST IN PRODUCING BIODIESEL FROM TREATED WASTE COOKING OIL
}

\author{
Taslim*, Meilia, Nike Taruna \\ Departemen Teknik Kimia, Fakultas Teknik Universitas Sumatera Utara, Sumatera Utara \\ Jl. Almamater Kampus USU Medan 20155, Indonesia \\ *E-mail : taslim_hr@yahoo.co.id
}

\begin{abstract}
Abstrak
Biodiesel merupakan bahan bakar alternatif untuk mesin diesel yang terbuat dari bahan baku minyak nabati maupun hewani. Treated Waste Cooking Oil (TWCO) adalah minyak jelantah yang diberikan pretreatment dengan karbon aktif. Tujuan dari penelitian ini adalah mengetahui potensi katalis campuran zeolit alam dan $\mathrm{CaO}$ yang berasal dari cangkang telur ayam dalam pembuatan biodiesel dengan bahan baku TWCO. Cangkang telur ayam dikalsinasi pada suhu $1000{ }^{\circ} \mathrm{C}$ dan waktu 2 jam. Pengaruh dari penggunaan katalis zeolit alam dan $\mathrm{CaO}$ diamati dalam percobaan ini. Sifat-sifat biodiesel seperti persen kemurnian, densitas, viskositas kinematik, dan titik nyala dievaluasi dan dibandingkan dengan Standar Nasional Indonesia (SNI). Pada penelitian yang dilakukan diperoleh yield biodiesel untuk katalis zeolit alam tunggal, $\mathrm{CaO}$ tunggal dan katalis campuran zeolit alam dan $\mathrm{CaO}$ yaitu 7,28\%; 51,17\%; dan 87,40\%. Biodiesel yang dihasilkan telah memenuhi SNI dan menunjukkan bahwa penambahan zeolit mampu meningkatkan kemampuan katalitik sehingga berpotensi sebagai katalis berbiaya murah untuk memproduksi biodiesel.
\end{abstract}

Kata kunci: biodiesel, kalsium oksida, transesterifikasi, TWCO, zeolit alam

\begin{abstract}
Biodiesel is an alternative fuel for diesel engines which is produced from either vegetable oils or animal fats. Treated Waste Cooking Oil (TWCO) was the pretreated WCO using activated carbon to reduce the high content of free fatty acid (FFA). The objective of this study was to discover the potential of catalyst which was the mixture of natural zeolite and $\mathrm{CaO}$ derived from the chicken eggshells in producing biodiesel with TWCO as feedstock. Chicken eggshells were calcined at the temperature of $1000{ }^{\circ} \mathrm{C}$ for 2 hours. Effect of using the catalyst, natural zeolite and $\mathrm{CaO}$, was investigated in this study. The properties of biodiesel such as methyl ester content, density, kinematic viscosity and flash point were evaluated and compared to the Indonesian Standard (SNI). In this study, the biodiesel yield for catalyst of natural zeolite, $\mathrm{CaO}$, and mixture of both were 7,28\%; 51,17\%; and $87,40 \%$ respectively. The biodiesel produced in this study was comparable to the SNI standard and that the addition of natural zeolite could enhance the catalytic activity. Therefore, it is highly potential as low-cost catalyst in producing biodiesel.
\end{abstract}

Keywords: biodiesel, calcium oxide, natural zeolite, transesterification, TWCO 


\section{Pendahuluan}

Dewasa ini, kebanyakan produsen bahan bakar memiliki minat terhadap bahan bakar terbarukan alternatif untuk menggantikan atau dicampurkan dengan bahan bakar dari petroleum. Bahan bakar alternatif tersebut dipercaya akan mudah didapatkan, ramah lingkungan dan mampu bersaing baik secara teknologi maupun harga [2]. Penggunaan bahan bakar bio sebagai pengganti bahan bakar fosil saat ini sedang diproduksi dengan intensitas yang meningkat [3]. Salah satu bahan bakar bio yang menjadi perhatian adalah biodiesel.

Sekitar 95\% dari produksi biodiesel di dunia dikonversi dari minyak yang dapat dikonsumsi. Penggunaan minyak yang dapat dikonsumsi pada produksi biodiesel telah menjadikan minyak yang dapat dikonsumsi serta biodiesel mengalami peningkatan harga hingga 1,5-2 kali lipat dibandingkan harga bahan bakar diesel [4]

Adapun upaya yang dapat dilakukan untuk mengatasi masalah biaya produksi biodiesel yaitu dengan menekan biaya bahan baku dengan memanfaatkan minyak jelantah yang merupakan limbah. Selain itu, pemanfaatan minyak jelantah sebagai bahan baku biodiesel tentunya akan mengurangi masalah kontaminasi dikarenakan penggunaan minyak ini akan mengurangi beban pemerintah dalam hal pembuangan limbah, pemeliharaan saluran pembuangan, dan pengolahan limbah minyak. Selain itu, penggunaan katalis heterogen untuk produksi biodiesel banyak dilakukan dikarenakan katalis heterogen memiliki keuntungan, diantaranya adalah tidak korosif, mudah dipisahkan dan ramah lingkungan serta ekonomis [8]. Untuk mendapatkan katalis kalsium oksida $(\mathrm{CaO})$ secara alami, maka kulit telur bekas merupakan sumber biomassa yang baik. Komponen utama dari kulit telur adalah kalsium karbonat $\left(\mathrm{CaCO}_{3}\right)$. Komponen kalsium karbonat akan dikonversi menjadi kalsium oksida dan karbon dioksida pada temperatur tinggi [16].

Adapun beberapa penelitian yang dilakukan untuk meningkatkan kinerja katalis dimana salah satunya dilakukan oleh Wu, dkk (2013) yang menyatakan bahwa aktivitas katalis $\mathrm{CaO}$ meningkat setelah digunakan dengan zeolit sebagai penyangga. Wu, dkk (2013) membuat katalis dengan menggiling $\mathrm{CaO}$ dan zeolit secara bersamaan kemudian dilakukan iradiasi pada campuran tersebut. Kesimpulan yang diperoleh dari penelitian tersebut menyebutkan bahwa berbagai logam alkali yang diisi pada alumino atau zeolit terbukti merupakan katalis basa padat yang efektif untuk transesterifikasi minyak nabati [15]. Untuk mengurangi penggunaan energi dalam pembuatan biodiesel, penelitian ini dilakukan dengan menggunakan katalis paduan $\mathrm{CaO}$ dan zeolit alam yang tidak diberikan perlakuan baik secara termal ataupun secara kimiawi dan diuji kemampuan katalis dalam menghasilkan biodiesel.

Berdasarkan uraian di atas, penelitian ini dilakukan dengan menggunakan minyak jelantah berbasis minyak kelapa sawit yang termasuk limbah rumah tangga dan reaktan metanol dengan katalis paduan $\mathrm{CaO}$ yang berasal dari limbah cangkang telur ayam dan zeolit alam sebagai bahan baku dalam pembuatan biodiesel melalui reaksi transesterifikasi.

\section{Teori}

Katalis homogen menghasilkan air limbah dengan volume besar yang harus diolah, dan hal ini secara signifikan meningkatkan biaya dan berdampak terhadap lingkungan pada prosesnya. Oleh karena itu, penggunaan katalis heterogen menjadi menarik karena katalis heterogen memiliki keuntungan, diantaranya adalah tidak korosif, mudah dipisahkan dan ramah lingkungan serta ekonomis [8].

Kapur tohor adalah kalsium oksida $(\mathrm{CaO})$ yang diperoleh dari kalsinasi bubuk kapur. Kapur tohor adalah material tak beracun yang tidak mahal dan ramah lingkungan. Aktivitas katalis dari kapur tohor dapat ditingkatkan dengan mengkonversinya menjadi kalsium metoksida $\left(\mathrm{Ca}\left(\mathrm{OCH}_{3}\right)_{2}\right)$. Dibandingkan dengan $\mathrm{CaO}$, katalis ini memiliki aktivitas yang lebih tinggi dan kelarutan yang lebih rendah pada reaksi transesterifikasi dengan minyak nabati [14]. Katalis yang berbasis kalsium (Ca) memiliki aktivitas katalis yang cenderung lebih tingi dimana diantaranya kalsium metoksida memiliki aktivitas katalis yang sangat baik dan juga memiliki waktu pakai yang panjang serta dapat mempertahankan keaktifannya bahkan setelah digunakan berulang kali [8].

Secara umum, katalis yang baik harus memenuhi beberapa syarat yaitu dapat menjadi katalis pada reaksi transesterifikasi dan esterifikasi, tidak terdeaktifasi oleh air, stabil, aktif pada temperatur rendah, dan memiliki selektivitas tinggi. Efisiensi katalis bergantung pada beberapa faktor yaitu luas permukaan spesifik, ukuran pori, volume pori dan konsentrasi sisi aktif [1].

Zeolit memiliki sifat yang unik dimana permukaan dalam sangat mudah diakses dan terdiri lebih dari $98 \%$ dari total luas permukaan. Luas permukaannya lebih kurang $300-700 \mathrm{~m}^{2} / \mathrm{g}$ [9]. Untuk reaksi transesterifikasi yang melibatkan Trigliserida rantai panjang maka zeolit dengan ukuran pori yang besar, aktivitas yang meningkat seiring dengan rasio $\mathrm{Si} / \mathrm{Al}$ dan memiliki sifat hidrofobik lebih diminati [2]. 


\section{Metodologi Penelitian}

Bahan Baku dan Pereaksi

Minyak jelantah diperoleh dari pedagang makanan ringan di lingkungan Jalan Sumatera, Medan, sedangkan cangkang telur ayam broiler diperoleh dari pedagang di Kantin Fakultas Teknik, Universitas Sumatera Utara. Metanol (kemurnian> 99,0\%) dibeli dari Merck, Jerman. Zeolit alam dibeli dari PT Rudang Jaya Medan.

\section{Persiapan Bahan Baku}

Minyak jelantah diberi pre-treatment menggunakan karbon aktif sebanyak $10 \%$ diaduk dengan kecepatan 250 rpm selama 30 menit [7, 10]. Filtrat diambil sebagai TWCO dan disimpan dalam wadah tertutup. Zeolit alam dihancurkan dengan ball mill dan diayak menggunakan ayakan 200 mesh. Sedangkan cangkang telur ayam dicuci dan dikeringkan, lalu dihancurkan dengan ball mill, serta diayak menggunakan ayakan 200 mesh. Preparasi $\mathrm{CaO}$ dilakukan dengan kalsinasi pada suhu $1.000{ }^{\circ} \mathrm{C}$ selama 2 jam [11].

\section{Prosedur Transesterifikasi}

TWCO sebanyak 50 gram dimasukkan ke dalam rangkaian peralatan transesterifikasi dan diaduk hingga mencapai suhu $65{ }^{\circ} \mathrm{C}$. Lalu ditambahkan pelarut metanol (dengan variasi rasio metanol terhadap TWCO sebesar 12:1 dan campuran katalis zeolit alam dan $\mathrm{CaO}$ sebanyak $8 \%$. Reaksi ini berjalan dengan pengadukan 700 rpm selama 3 jam. Setelah reaksi selesai, hasil reaksi kemudian didinginkan. Campuran hasil transesterifikasi ini dipisahkan dari katalis padatnya dengan menggunakan filtrasi vakum. Filtrat kemudian dimasukan ke dalam corong pisah hingga produk metil ester dan gliserol terpisah dengan baik. Setelah itu lapisan bawah dipisahkan dari corong pisah dan produk metil ester dicuci dengan menggunakan air panas beberapa kali untuk menghilangkan sisa gliserol dan katalis, lalu dipisahkan dari metanol dan air dengan cara pemanasan pada suhu $105{ }^{\circ} \mathrm{C}$. Metil ester hasil transesterifikasi kemudian ditentukan berat, dianalisis kemurniannya, dan dihitung persen yield biodieselnya.

\section{Analisis Kimia \\ Kompoisisi Bahan Baku dan Kemurnian Biodiesel}

Komposisi bahan baku TWCO dan kemurnian biodiesel dianalisis dengan menggunakan instrumen Gas Chromatography (GC).

\section{Analisis Densitas, Viskositas dan Titik Nyala Biodiesel}

Untuk analisis densitas dan viskositas menggunakan instrumen Viscosimeter Ostwald di
Laboratorium Penelitian, Departemen Teknik Kimia, Fakultas Teknik, Universitas Sumatera Utara, Medan. Analisis titik nyala biodiesel dengan instrumen closed cup flash tester.

\section{Hasil dan Pembahasan \\ Hasil Analisis Bahan Baku TWCO}

Tabel 1 menunjukkan data komposisi asam lemak yang diperoleh melalui analisis menggunakan instrumen GC.

\section{Tabel 1. Komposisi Asam Lemak dari TWCO}

\begin{tabular}{|l|r|}
\hline Komponen Penyusun & $\begin{array}{c}\text { Komposisi \% } \\
\text { (b/b) }\end{array}$ \\
\hline Asam Laurat (C12:0) & 0,3204 \\
\hline Asam Miristat (C14:0) & 0,9069 \\
\hline Asam Palmitat (C16:0) & 39,2970 \\
\hline $\begin{array}{l}\text { Asam Palmitoleiat } \\
\text { (C16:1) }\end{array}$ & 0,1629 \\
\hline Asam Stearat (C18:0) & 3,9210 \\
\hline Asam Oleat (C18:1) & 44,9953 \\
\hline Asam Linoleat $(\mathrm{C} 18: 2)$ & 9,6922 \\
\hline Asam Linolenat (C18:3) & 0,2174 \\
\hline Asam Arakidat (C20:0) & 0,3474 \\
\hline $\begin{array}{l}\text { Asam Eikosenoat } \\
\text { (C20:1) }\end{array}$ & 0,1395 \\
\hline
\end{tabular}

Berdasarkan data pada Tabel 1, dapat ditentukan bahwa berat molekul asam lemak TWCO adalah 271,467 gram/mol. Berdasarkan hasil analisis GC, komponen asam lemak yang utama pada sampel TWCO yaitu asam lemak tidak jenuh berupa asam oleat sebesar 44,99\% dan asam lemak jenuh berupa asam palmitat sebesar 39,29\%. Selain itu, dilakukan analisis kadar FFA pada TWCO dengan standar AOCS 5a - 40 dan diperoleh kadar FFA pada TWCO sebesar 0,4\%.

\section{Morfologi Katalis}

Dalam penelitian ini, dilakukan analisis terhadap morfologi katalis menggunakan Scanning Electron Microscope (SEM).

Gambar 1(a) menunjukkan morfologi zeolit alam yang memiliki sisi - sisi yang tajam dan tidak beraturan. Gambar 1(b) menunjukkan abu cangkang telur yang beraturan dan memiliki permukaan yang cenderung datar. Sedangkan Gambar 1(c) menunjukkan campuran zeolit alam dan abu cangkang telur, dimana abu cangkang telur yang berwarna lebih terang terdispersi merata pada permukaan zeolit alam yang memiliki warna lebih gelap. 


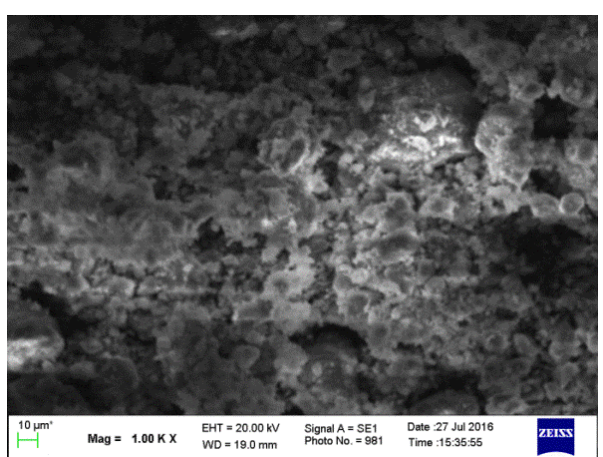

(a)

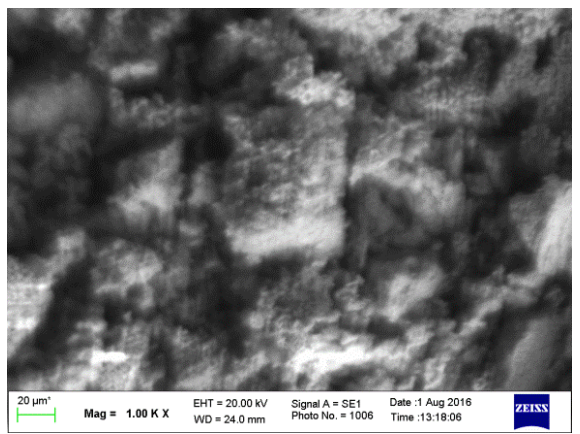

(b)

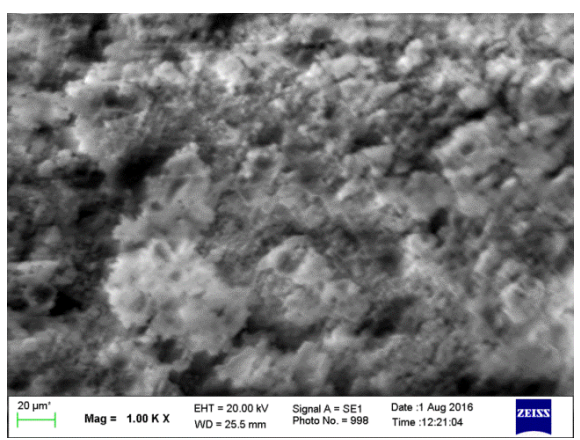

(c)

Gambar 1. Hasil Analisis SEM (a) Zeolit Alam (b) Abu Cangkang Telur (c) Paduan Katalis Zeolit Alam/CaO dari Abu Cangkang Telur Ayam dengan Perbesaran 1.000 Kali

\section{Pengaruh Variasi Katalis terhadap Yield Biodiesel}

Gambar 2 menunjukkan perbandingan variasi katalis terhadap yield biodiesel dimana terlihat bahwa yield biodiesel yang dihasilkan dengan katalis zeolit alam, $\mathrm{CaO}$, dan katalis campuran zeolit alam dan $\mathrm{CaO}$ yaitu sebesar 7,28\%; 51,17\%; dan $87,40 \%$. Untuk pembuatan biodiesel dengan katalis zeolit alam dengan yield yang rendah dan \%kemurnian biodiesel yang tidak sesuai standar tersebut telah sesuai dengan penelitian yang dilakukan oleh Kay, dkk (2012) dimana katalis zeolit alam dengan bahan baku minyak jatropha yang berkualitas rendah tidak dihasilkan metil ester [6]. Sedangkan untuk perbandingan katalis $\mathrm{CaO}$ dan campuran katalis dimana penambahan zeolit alam mampu menghasilkan yield yang lebih tinggi. Hal ini dapat disebabkan oleh penambahan senyawa penyangga mampu meningkatkan dispersi katali dalam campuran, sehingga mampu mempengaruhi kemampuan katalitik dari katalis tersebut [13].

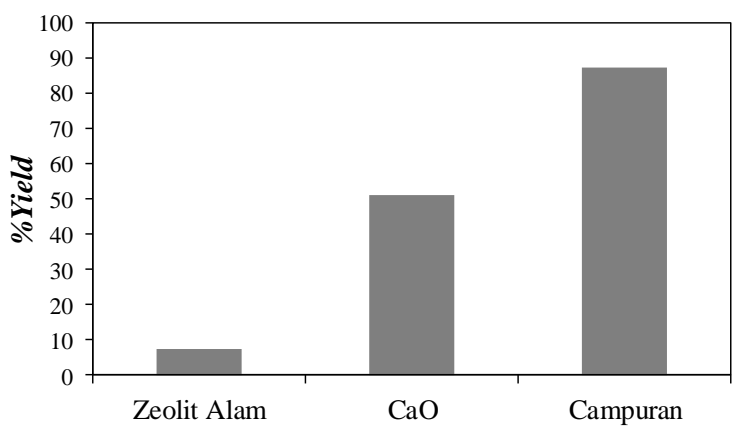

Gambar 2. Perbandingan Variasi Katalis terhadap Yield Biodiesel

\section{Pengaruh Komposisi Katalis terhadap Yield Biodiesel}

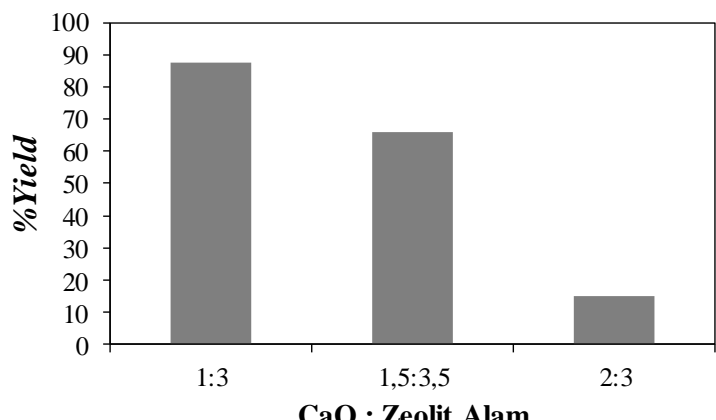

Gambar 3. Perbandingan Komposisi Katalis terhadap Yield Biodiesel

Gambar 3 menunjukkan perbandingan komposisi katalis, yakni komposisi $\mathrm{CaO}$ : zeolit alam terhadap yield biodiesel dimana terlihat bahwa yield biodiesel yang dihasilkan semakin menurun dengan komposisi $\mathrm{CaO}$ yang semakin meningkat dalam campuran. Kajian ini bertujuan untuk menentukan komposisi $\mathrm{CaO}$ dan zeolit alam yang terbaik dalam campuran katalis. Yield biodiesel yang diperoleh dengan komposisi $\mathrm{CaO}$ : zeolit alam sebesar 1:3; 1,5:3,5; dan 2:3 yaitu sebesar $87,40 \%$; $65,89 \%$; dan $15,19 \%$.

Hal ini sesuai dengan percobaan yang telah dilakukan oleh Wu, dkk (2013) yang menggunakan katalis dengan komposisi 30\% massa $\mathrm{CaO}$ pada Zeolit $\mathrm{NaY}$ dengan iradiasi microwave selama 20 menit dan merupakan rasio 
katalis terbaik pada percobaan tersebut dan dengan rasio katalis tersebut, perbandingan mol bahan baku 9:1, jumlah katalis $3 \%$ dan temperatur $65^{\circ} \mathrm{C}$, dihasilkan biodiesel dengan yield melebihi $95 \%$ dengan waktu reaksi 3 jam [15].

\section{Analisis Sifat Fisik Biodiesel}

Produk biodiesel dari penggunaan campuran katalis zeolit alam dan $\mathrm{CaO}$ dari cangkang telur ayam dibandingkan dengan standar SNI 71822015 [12] yang dapat dilihat pada Tabel 2.

Tabel 2. Perbandingan Sifat Fisik Biodiesel dengan Standar SNI

\begin{tabular}{|l|c|c|}
\hline \multicolumn{1}{|c|}{ Parameter } & Produk & SNI \\
\hline Kadar Ester $(\%)$ & 99,32 & $\geq 96,5$ \\
\hline $\begin{array}{l}\text { Densitas }\left(\mathrm{kg} / \mathrm{m}^{3}\right) \\
\text { pada } 40{ }^{\circ} \mathrm{C}\end{array}$ & 860 & $\begin{array}{c}850- \\
890\end{array}$ \\
\hline Titik Nyala $\left({ }^{\circ} \mathrm{C}\right)$ & 158 & $>100$ \\
\hline $\begin{array}{l}\text { Viskositas Kinematik } \\
(\mathrm{cSt}) \text { pada } 40^{\circ} \mathrm{C}\end{array}$ & 4,69 & $\begin{array}{c}2,3- \\
6,0\end{array}$ \\
\hline
\end{tabular}

Tabel 2 menunjukkan bahwa produk hasil transesterifikasi TWCO menggunakan katalis campuran zeolit alam dan $\mathrm{CaO}$ dari cangkang telur ayam telah memenuhi sebagian Standar Nasional Indonesia (SNI 7182-2015).

\section{Kesimpulan}

1. Asam lemak utama yang terdapat dalam bahan baku minyak jelantah adalah asam oleat sebesar 44,49\% dan asam palmitat sebesar $39,89 \%$.

2. Penambahan zeolit alam dapat meningkatkan kemampuan katalitik pada katalis $\mathrm{CaO}$ dari cangkang telur ayam, hal ini ditandai oleh peningkatan yield biodiesel.

3. Komposisi $\mathrm{CaO}$ terhadap zeolit alam terbaik yang dapat digunakan untuk transesterifikasi TWCO adalah 1:3.

4. Analisis fisik pada biodiesel dengan yield tertinggi berupa analisis densitas, viskositas kinematik, kemurnian dan titik nyala memperoleh hasil berturut - turut sebesar $872,813 \mathrm{~kg} / \mathrm{m}^{3}, 5,4 \mathrm{cSt}, 99,32 \%$ dan $158{ }^{\circ} \mathrm{C}$. Hasil yang diperoleh telah memenuhi Standar Nasional Indonesia (SNI 7185:2015) untuk biodiesel.

\section{Daftar Pustaka}

[1] A. A. Refaat, Biodiesel Production Using Solid Metal Oxide Catalysts, International Journal of Environment and Science Technology, 8, (2011).

[2] A. F. Lee, J. A. Bennett, J. C. Manayil, and K. Wilson, Heterogeneous Catalysis for Sustainable Biodiesel Production via Esterification and Transesterification, Chemical Society Review, 43, (2014).
[3] A. K. Endalew, Y. Kiros, and R. Zanzi, Heterogeneous Catalysis for Biodiesel Production from Jatropha curcas Oil (JCO), Energy, 36, (2011).

[4] L. F. Chuah, S. Yusup, A. R. A. Aziz, A. Bokhari, J. J. Klemes, and M. Z. Abdullah, Intensification of Biodiesel Synthesis from Waste Cooking Oil (Palm Olein) in a Hydrodynamic Cavitation Reactor : Effect of Operating Parameters on Methyl Ester Conversion, Chemical Engineering and Processing, 95, (2015).

[5] H. V. Lee, J. C. Juan, N. F. B. Abdullah, N. M. F. Rabiah, and Y. H. T. Yap, Heterogeneous Base Catalysts for Edible Palm and Non-Edible Jatropha-based Biodiesel Production, Chemistry Central Journal , (2014).

[6] K. H. Kay and S. M. Yasir, Biodiesel Production from Low Quality Crude Jatropha Oil Using Heterogeneous Catalyst, APCBEE Procedia: ICCP 2012, 3, (2012) 2212-6708.

[7] L. S. Kheang, F. Subari, and S. A. S. A. Kadir, Pre-Treatment of Palm Olei-Derived Used Frying Oil As A Feedstock for NonFood Applications, Journal of Oil Palm Research, 23, (2011) 1185-1192.

[8] O. Mohamed, F. Bensaheb, H. Bano, S. Behl, and M. Jarrar, Evaluating The Role of The Appropriate Catalysts on The Efficacy of Biodiesel Production From Waste Cooking Oil. Review Article, Scholars Academic Journal of Biosciences (SAJB), (2015).

[9] P. Payra, P. K. Dutta, S. M. Auerbach., and K. A. Carrado, Handbook of Zeolite Science And Technology, Marcel Dekker Inc., United States of America, 2003.

[10] R. S. Putra, T. S. Julianto, P. Hartono, R. D. Puspitasari, and A. Kurniawan, Pre-treatment of Used-Cooking Oil as Feed Stocks of Biodiesel Production by Using Activated Carbon and Clay Minerals, (2014).

[11] S. Sirisomboonchai, M. Abuduwayiti, G. Guan, C. Samart, S. Abliz, X. Hao, K. Kusakabe, and A. Abudula, Biodiesel Production from Waste Cooking Oil Using Calcined Scallop Shell As Catalyst, Energy Conversion and Management, 95, (2015) 242-247.

[12] SNI 7182:2015, Biodiesel, Jakarta: Badan Standardisasi Nasional, (2015).

[13] T. Moteki, Y. Murakami, S. Noda, S. Maruyama, and T. Okubo, Zeolite Surface As A Catalyst Support Material for Synthesi of Single-Walled Carbon Nanotubes, The Journal of Physical Chemistry, (2011).

[14] W. Suwanthai, V. Punsuvon, and P. Vaithanomsat, Optimization of Biodiesel 
Production from A Calcium Methoxide Catalyst Using A Statical Model, Korean Journal of Chemical Engineering, (2015).

[15] Wu, Haitang., Junhua Zhang, Qin Wei, Jilu Zheng, dan Jianan Zhang, Transesterification of Soybean Oil to Biodiesel Using Zeolite Supported $\mathrm{CaO}$ As Strong Base Catalysts, Fuel Processing Technology, 109, (2013).

[16] Y. H. Tan, M. O. Abdullah, C. N. Hipolito, and Y. H. T. Yap, Waste Ostrich- and Chicken-Eggshells As Heterogeneous Base Catalyst for Biodiesel Production from Used Booking Oil : Catalyst Characterization and Biodiesel Yield Performance, Applied Energy, 160, (2015). 